\title{
Fruit Cracking in Tomato
}

\author{
M.M. Peet ${ }^{1}$
}

Additional index words. Lycopersicon esculentum, splitting, fruit quality, physiological disorders, russeting

Summary. The environmental and physiological causes of cracking or splitting of soft fruits and citrus as they ripen are not well understood. This paper explores factors contributing to radial cracking in tomatoes, gives suggestions for prevention of cracking, and suggests directions for future research. Fruit cracking occurs when there is a rapid net influx of water and solutes into the fruit at the same time that ripening or other factors reduce the strength and elasticity of the tomato skin. In the field, high soil moisture tensions suddenly lowered by irrigation or rains are the most frequent cause of fruit cracking. Low soil moisture tensions reduce the tensile strength of the skin and increase root pressure. In addition, during rain or overhead irrigation, water penetrates into the fruit through minute cracks or through the corky tissue around the stem scar. Increases in fruit temperature raise gas and hydrostatic pressures of the pulp on the skin, resulting in immediate cracking in ripe fruit or delayed cracking in green fruit. The delayed cracking occurs later in the ripening process when minute cracks expand to become visible. High light intensity may have a role in increasing cracking apart from its association with high temperatures. Under high light conditions, fruit soluble solids and fruit growth rates are higher. Both of these factors are sometimes associated with increased cracking. Anatomical characteristics of cracksusceptible cultivars are: 1 ) large fruit size, 2) low skin tensile strength and/ or low skin extensibility at the turning to the pink stage of ripeness, 3) thin skin, 4) thin pericarp, 5) shallow cutin penetration, 6) few fruits per plant, and 7) fruit not shaded by foliage. Following cultural practices that result in uniform and relatively slow fruit growth offers some protection against fruit cracking. These practices include maintenance of constant soil moisture and

${ }^{\prime}$ Department of Horticultral Science, Box 7609, North Carolina State University, Raleigh, NC 27695-7609. 
good Ca nutrition, along with keeping irrigation on the low side. Cultural practices that reduce diurnal fruit temperature changes also may reduce cracking. In the field, these practices include maintaining vegetative cover. Greenhouse growers should maintain minimal day/night temperature differences and increase temperatures gradually from nighttime to daytime levels. For both field and greenhouse tomato growers, harvesting before the pink stage of ripeness and selection of crackresistant cultivars probably offers the best protection against cracking. Areas for future research include developing environmental models to predict cracking and exploring the use of $\mathrm{Ca}$ and gibberellic acid (GA) sprays to prevent cracking.

$\mathrm{F}$ ruit cracking in tomatoes as well as in other fleshy fruits such as apples, grapes, cherries, and citrus can cause serious economic losses. Cracks reduce marketability and provide entry for insects and fungi, caus- ing significant income loss in the fresh market and processing tomato industries (Calbo, 1990; Cotner et al., 1969; Walter, 1967). There are many types of fruit cracking: longitudinal or burst cracking; ring or concentric cracking (Fig. 1 upper and lower right); crazing or russeting; star or radial cracking (Fig. 1 upper left, severe; lower left, mild); lenticilar cracking; and core failure. This review concentrates on star or radial cracking in tomatoes, but also includes recent advances in understanding the causes of fruit russeting in tomatoes.

Although fruit cracking in apples, cherries, and tomatoes has been investigated since the 1930s, and breeders have incorporated crack resistance into many modern-day tomato cultivars, little progress has been made in understanding the physiology of fruit cracking in any of these crops. In turn, this has made it difficult to recommend preventive measures. With respect to tomato production in Japan, Kamimura (1977) reported, "No cultural practices have been found that can consis-

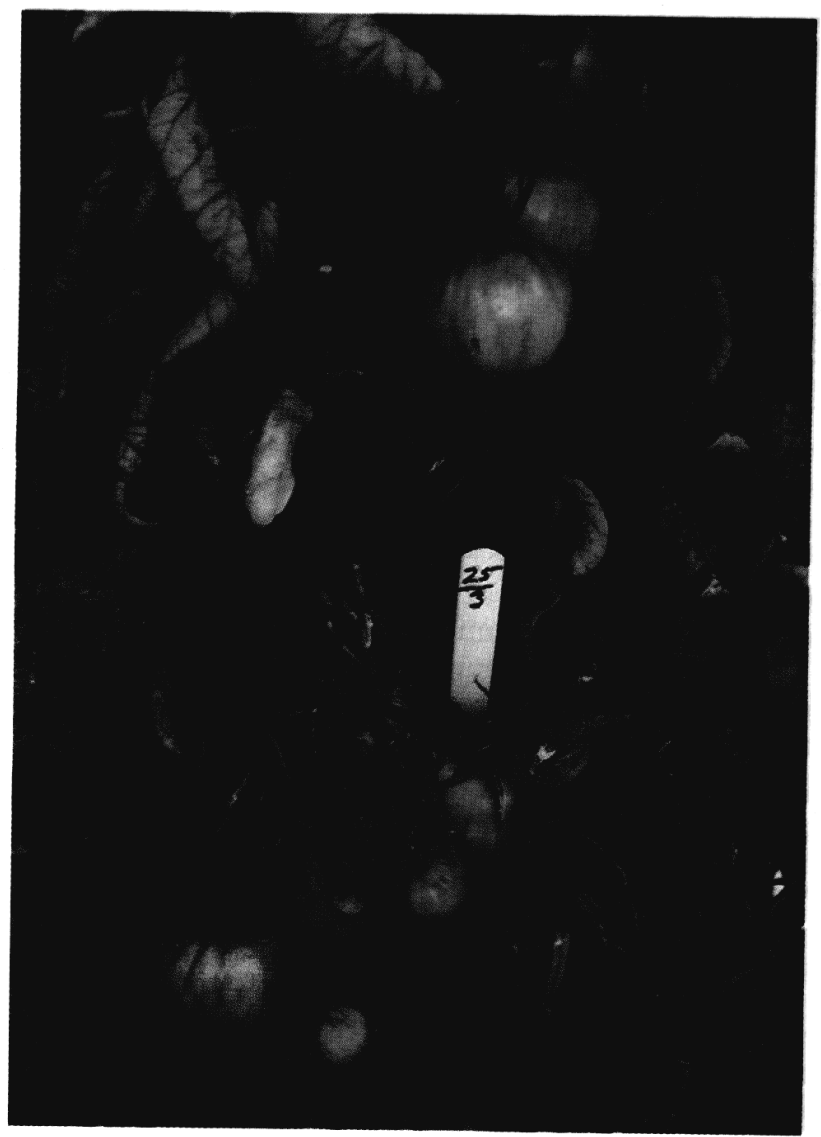

Fig. 1. Types of cracking in tomatoes grown in the field in a trellis tomato-production area in the mountains of western North Carolina. Upper left: sepere radial cracking; upper right: concentric cracking; lower right: a form of concentric cracking referred to in the mountains as "rain checking"; lower left: mild radial cracking and mild rain checking. tently reduce the occurrence of cracking." Part of the problem is that fruit cracking is episodic in nature, ranging from severe in some years in certain locations to virtually unknown in others. Fruit cracking is difficult to study, even in controlled conditions, because we lack experimental methods to induce cracking. The most common technique used to screen tomatoes for susceptibility to cracking is vacuum infiltration of water into the detached fruit. With this technique, first described by Hepler (1961), a vacuum pump pulls air out of fruit submerged in distilled water. When the vacuum is released, water rushes into the fruit causing cracking. Although shown by Kamimura (1977) to correlate with field resistance to cracking, this technique may not be the physiological equivalent of field cracking induced by irrigation or rainfall (Calbo, 1990) because after vacuum infiltration the intercellular spaces are filled by water rather than by gas.

Although the physiological basis of fruit cracking is not understood, growers and researchers have associated a number of environmental, cultural, and anatomical factors with high incidence of fruit cracking. This article examines these factors, proposes a physiological explanation, and suggests future research directions.

\section{Theory 1}

Irregular watering, especially going from very dry to very wet conditions, causes cracking. This is the explanation given most often to explain cracking in both tomatoes and apples. After an extensive study of field tomatoes, Frazier (1934) concluded that, "The most perfectly consistent effect has been the cracking following application of water to fruits or soil." Kamimura et al. ( 1972) proposed the following explanation, based on their studies of the effects of soil-moisture levels on fruit skin, for cracking of tomatoes after rain. They showed that high soil moisture lowered the tensile strength of tomato fruit skin. Because of this low tensile strength, the fruit enlarged rapidly and developed many minute cracks, These minute cracks later developed into visible cracks. Under low soil moisture, Kamimura et al. (1972) found that the tensile strength of the skin was greater.. As a result, plants grew more slowly and had fewer 
minute cracks. Changes in soil moisture during fruit growth also affected skin strength. Skin strength increased if soil moisture content decreased. Conversely, skin strength decreased if soil-moisture content increased. In fact, changes from low to high soil moisture lowered skin strength compared to continued growth under any moisture regime. Such changes typically occur when drought is relieved by irrigation or rain. Cracking is particularly likely with continued wet weather or overhead irrigation because water enters the fruit through these minute cracks.

The observations of Kamimura et al. (1972) appear to explain the greater frequency of cracking in the rain-fed eastern United States production areas compared to irrigated western tomatogrowing regions. Screening for fruit cracking is difficult in California because it is so rare (A. Stevens, personal communication). However, California-bred, fresh-market cultivars often crack under eastern conditions ( $\mathrm{R}$. Gardner, personal communication). Fruit cracking in California processing tomatoes is only a problem near the end of the summer when seasonal rains begin (C. Rick, personal communication). Possibly, the reason fruit cracks in California near the end of the summer, but not before, is that high temperature and high evapotranspiration maintains soil-moisture levels reasonably low and skin tensile strength high for most of the season. Fall rains, accompanied by lower temperatures and high humidities, however, raise the soil moisture, reducing the skin strength and causing minute cracks (Kamimura et al., 1972). These cracks act both as focal points for skin stresses, leading to ruptures and cracking (Brown and Considine, 1982), and allow water to penetrate into the fruit, causing swelling and bursting. Kamimura et al. (1972) and Frazier (1934) noted that absorption of external moisture by minute cracks, corky spots, or the corky layer around the stem was one of the main factors associated with cracking. Cracking after rain is difficult to prevent, but mechanical root pruning with cultivation equipment before an anticipated rainfall could conceivably reduce root pressure and prevent cracking.

The finding by Kamimura et al. (1972) of soil moisture-induced changes in skin strength explains many episodes of fruit cracking of tomatoes in the field. Fruit cracking also can occur, however, in environments with little day-to-day variation in water and without the plants ever having been water-stressed, as in greenhouse tomato production. To test the hypothesis that even the relatively small daily cycles ofwetting and drying could cause fruit cracking in greenhouse tomatoes, Abbott et al. (1986) increased the frequency of daily waterings from one long watering to four short waterings. Equal and adequate amounts of water were applied to all treatments. Although soil moisture fluctuated somewhat less with four daily waterings, cracking decreased only slightly.

Taking another approach to finding out the causes of fruit cracking in greenhouses, Peet and Willits (unpublished data) tested the hypothesis that reducing the amount of water applied reduces cracking. In Fall 1989 and Spring 1990, they kept the number of waterings the same, but increased the amount of water. In both spring and fall, the least fruit cracking on a percentage basis was observed in the treatment receiving the least water. Total yield was not affected by the watering treatments. In field-grown tomatoes, Brown and Price (1934) also found that reduced watering decreased the degree of cracking in tomatoes. Presumably, this is because of the greater tensile strength in the skin of fruit from low moisture grown plants (Kamimura et al., 1972). It is difficult to try to control tomato fruit cracking by decreasing the amount of water. Peet and Willits' driest treatment had a slightly higher (but still very low) incidence of blossom-end rot, even though plants did not wilt significantly.

Thus, the effects of wet and dry soil on tomato skin strength (Kamimura et al., 1972) explain many, but not all, cracking incidents. Other factors that may be important are discussed below.

\section{Theory 2}

High temperatures and high light cause cracking. In the greenhouse and in the field, cracking often peaks at the time of peak temperatures and light. Apples grown on the outside of the tree and exposed to the sun are most likely to crack (Verner, 1935). High temperatures in general, and sudden high temperatures in midafternoon in particular, caused redripe tomato fruit to crack in the green- house (Frazier, 1947). An explanation for these temperature effects is given by recent studies with grapes. Raising fruit temperature dramatically increased the pressure exerted by the pulp on the skin and at the same time decreased skin stiffness and strength, increasing the incidence of splitting (Lang and During, 1990).

Shading the entire plant with muslin reduced, but did not eliminate, tomato fruit cracking (Brown and Price, 1934). However, photosynthesis and fruit sugar levels may have been reduced by shading, which could have affected cracking indirectly. Water moves from an area of the plant with low sugar concentration to an area of high sugar concentration. Therefore, the higher the fruit-sugar levels, the greater the tendency of water to move into the fruit from the stem and leaves, exerting a greater pressure on the skin. In cherries, high osmotic concentration of the fruit juice is associated with cracking susceptibility (Ackley and Krueger, 1980). Indirect evidence for the importance of fruit soluble solids is presented in the observation of Considine and Kriedemann (1972), who found that splitting of grapes occurs when they are submerged in solutions of low osmotic potential. The amount of splitting was determined by differences in osmotic potential between the fruit and the solution, with skins of splittingsusceptible cultivars bursting at lower osmotic potentials than skins of resistant cultivars. There is also evidence against a role for high fruit osmotic potential in cracking. Andersen and Richardson (1982), however, were not able to relate rain-induced cracking of a sweet cherry cultivar to percentage soluble solids, osmotic potential, turgor potential, or fruit water potential. In tomatoes, Frazier (1934) was not able to relate cracking to carbohydrate constituents.

To determine ifcracking could be reduced by lowering sugar levels in tomato fruit, Peet and Willits (unpublished data) girdled the phloem between the stem and fruit clusters in a fall crop ofgreenhouse tomatoes. The fruit stem just above the calyx was placed in a balsa-wood mold. Hot wax was poured over the mold so that all the green tissue on the stem was killed. Water moves into the fruit through the conducting tissues, which are nonliving; these tissues were not damaged by girdling. Girdling killed the living tis- 
sues of the phloem through which sugars reach the fruit. The fruit enlarged and ripened normally, but soluble solids were reduced from 3.49 to $3.07{ }^{\circ}$ Brix. Cracking was eliminated in the girdled fruit, presumably because of the reduced soluble solids levels. Nongirdled and incompletely girdled fruit on the same cluster continued to crack.

\section{Theory 3}

Aspects of fruit anatomy may predispose cultivars to crack. Skin characteristics necessary for crack resistance have been characterized best by Kamimura et al. (1972). They showed that both high skin tensile strength and high elasticity from the turning stage to the pink stage ofripening were important. Resistant cultivars all had at least one or both of these characteristics.

Other fruit characteristics associated with crack resistance are 1) small size (Gill and Nandpuri, 1970); 2) thick skin (Gill and Nandpuri, 1970); 3) deep penetration of cutin into the skin (Hankinson, 1979); 4) small fruit diameter; 5) many fruit per plant; and 6) semideterminate plant growth habit (Young, 1958).

Certain fruit shapes and sizes predispose fruit to cracking, as Considine and Brown (1981) point out in their discussion of the physics of fruit cracking. As a fruit increases in size, the physical stress on the enclosing membrane (the skin) increases, and cracks occur in areas of the fruit where stress is greatest. In a tomato fruit, stress is greatest in the skin near the calyx. The star or radial cracking seen in tomatoes is that predicted to occur at an unreinforced hole in the surface of a membrane. Cracks do not occur randomly around the calyx, but rather occur between the locules. Frazier and Bowers (1947) attributed interlocular splitting to the "observed inherent anatomical weakness of septae tissue" 'and with differential growth rates smoothing out "the creases of the stem end, lying above these septae."

The pattern of vascularization also may be important in conferring resistance to cracking in tomato fruit (Cotner et al., 1969). Lang and Thorpe (1989) proposed that imbalances in relative influx and efflux of water into the fruit caused cracking. A cultivar with extensive vascular tissue could be less susceptible to these imbalances. The development of an abscission layer between the calyx and the fruit 10 days after the first color change (McCollum and Skok, 1960) adds an interesting dimension to water relations in the fruit during the late stages of ripening. The abscission zone is known to reduce the import of carbohydrates into the fruit. Conceivably, it could also create a backpressure that would reduce the ability of water to move rapidly out of the fruit when fruit temperatures rise.

\section{Theory 4}

Excessively rapid fruit growth causes cracking. Tomato fruit lacks secondary development of the cell walls and has no way to stop fruit expansion except through regulation of water pressure (Considine and Brown, 1981). Thus, rapidly growing fruit might be especially predisposed to cracking. Reduced cracking in cultivars with many fruit (Young, 1958) could be a result of competition among the fruits for carbohydrates, thus reducing fruit growth rates. In the field, Frazier (1935) found that pruning of sideshoots and staking of tomatoes increased cracking compared to nonpruned, nonstaked plants, but trimming an additional two-thirds of the leaves on the main stem from the staked plants decreased cracking. He suggested that this was because fruit growth rates were highest in the pruned, staked plants with mainstem leaves intact. In greenhouse tomato production, Dutch researchers (Bakker and Janse, 1988; Schilstra-vanVeelen and Bakker, 1985) demonstrated a relationship between rapid fruit growth and skin crazing or russeting. Russeting is a form of cracking in which minute cracks develop all over the surface of the fruit. Fruit that received more assimilates to enhance growth were more likely to crack. If fewer tomatoes were present on the plant, cracks were more likely. Topping the plants, removing sideshoots, lowering the conductivity of the fertilizer solution, and widening the spacings between plants all increased cracking.

Peet and Willits (unpublished data) noted that the incidence of radial cracking in greenhouse tomatoes is highest at the end of the season when fewer fruit are on the plant. This is true at the end of the spring season, when temperature and light were high, and of the fall season, when temperature and light were low. In a separate study, pruning fruit to two per cluster also increased cracking. In both these stud- ies, however, it is not clear if cracking increased because the supply of assimilates to each fruit was increased, or because the supply of water from the root was divided among fewer fruit.

\section{Theory 5}

Some cultivars crack more than others because of genetic differences. Cultivar differences in susceptibility to fruit cracking clearly exist (Abbott et al., 1986), but the physiological basis of these differences is far from clear. As discussedin Theory 3, a tough, stretchy skin at the turning to the pink stage and small fruit size offer some protection. These generalizations may apply only to tomatoes, however, as growth rates and fruit size of 41 nectarine clones were independent of cracking susceptibility (Fogle and Faust, 1976).

Another factor may be plant architecture. Shading of the tomato fruit by leaves was thought to account for cracking resistance in at least one cultivar (Frazier, 1952). Presumably, this shading reduces daytime fruit temperatures, which in turn, decreases fruit swelling during the day. Sideshoot pruning (Bakker and Janse, 1988) increases cracking, so cultivars that are vegetatively vigorous may also be more resistant to cracking.

Although great strides have been made by breeders in increasing the crack resistance of modern tomato cultivars, the genetics of crack resistance is not well understood. In his review, Walter (1967) stated that no researchers have concluded that inheritance of cracking resistance is simple. Different types of cracking including concentric, burst, and radial probably are controlled by different sets of genes. Even when considering only one type of cracking, direct selection for resistance is difficult because many genes seem to be responsible, heritability is low, and environmental influence is high (Cuartero et al., 1981). In addition, environmental factors affected early and total fruit cracking differently (Cortes et al., 1983).

\section{Theory 6}

High differentials between day and night temperatures increase cracking. Several years ago, a North Carolina greenhouse tomato grower suggested to me that sudden temperature increases from night to day cause cracking. Recently, the effects of high

Continued on page 222) 
(Continued from page 219)

day/night temperature differentials have been demonstrated experimentally (Bakker and Janse, 1988) with respect to fruit crazing, lending support to his suggestion. Fruit cooling, which occurs at night, would be expected to contract bulky fruits such as tomatoes (Corey and Tan, 1990). This negative pressure could suck in moisture that is condensed or otherwise present on the fruit surface, and also could draw in moisture from the plant itself. As temperatures rise during the day and the fruit heats up in the sun, positive pressures build inside the fruit, stretching the gas-impermeable tomato skin outward as the fruit expands in volume (Corey and Tan, 1990). Presumably, the greater the day/night differential, the greater the stress on the skin.

\section{Theory 7}

High humidity increases cracking. High humidity, or changes between day and night humidity, have been associated with increased cracking in several studies. It is not clear if high humidity per se had an effect in these studies or whether the vapor pressure deficit was also lower. Low vapor-pressure deficits decrease transpiration, and thus, may increase root pressure. High humidity increased tomato fruit cracking in the greenhouse, especially at high temperatures (Byari, 1984). Humidity effects on fruit cracking are probably related to gas and water pressure increases. The tomato skin is $97 \%$ gas-impermeable (Corey and Tan, 1990). As gas and water pressures increase in the fruit because of a temperature increase or an increase in water supply, the only way this outward pressure can be relieved is if the skin expands or if water is drawn out of the fruit and back into the plant. Movement of water back into the plant is unlikely to occurwhen humidity is high, because transpiration is reduced and root pressures are high. Under these conditions, even if cracking does not occur immediately, pressure can weaken the cuticle, causing minute cracks that later develop into visible cracks (Bakker and Janse, 1988). The effects of day/ night humidity variations are less clear. Schilstra-van Veelen and Bakker (1985) found the least skin crazing in the greenhouse when nighttime relative humidity was low and daytime relative humidity was high. In the field, however, Frazier and Bowers (1947) observed the most cracking following periods of low nighttime humidity and high daytime humidity.

Summary of conditions where cracking is likely. According to the above theories, the greatest probability of cracking occurs when a largefruited cultivar sets relatively few fruit. These fruit have a high soluble-solids content and are exposed to direct sun. The skin of this cultivar has little ability to stretch or resist puncture from the turning stage to the pink stage of ripening. Culturally, the cultivar is grown under conditions that result in rapid fruit growth, such as wide spacing, low conductivity of the fertilizer solution, and the removal of sideshoots and some fruit. Fruit are harvested well after the mature-green stage. Growing conditions are such that the leaves provide ample carbohydrates. Nighttime temperatures are low with high daytime temperature and humidity. Soil moisture is either too high, or is low and then suddenly increases when fruit are in the pink stage. Water is present on the fruit surface for long periods of time.

What can be done to prevent cracking To produce large, untracked red-ripe fruit in cultivars with thin skin and high soluble solids is challenging. Because home gardeners and roadside or specialty growers prefer this type of cultivar, and because they harvest at the pink stage or later, they are much more likely than commercial freshmarket tomato growers to have problems with cracking. Thus, the easiest way to decrease cracking is to use commercial cultivars selected for cracking resistance and to harvest tomatoes at the green-mature stage.

In addition, consistency in watering is the key factor in both home gardens and commercial production. Relieving water stress suddenly is the most certain means of cracking fruit. Close row spacing and shading will reduce cracking, probably because fruit size, soluble solids, and fruit temperatures decrease. Maintaining plants at low to medium soil moisture is preferable in the greenhouse or where rain is not likely during the growing season. Watering proportionately less as fruit are removed progressively up the vine also may decrease the incidence of cracking, assuming it can be done without unduly stressing the plants and risking blossom-end rot.

Good $\mathrm{Ca}$ nutrition is important for prevention of cracking in tomatoes and most other fruits, except possibly nectarines (Fogle and Faust, 1976), and also will help protect against blossom-end rot if water levels get too low (Simon, 1978). In apples, cherries, and tomatoes, formulations of $\mathrm{Ca}$ and/ or GA have been used with varying success to reduce cracking (Byers et al., 1990; Dickinson and McCollum, 1964; Larson et al, 1983). GA sprays appear to act by making the skin more elastic, while the $\mathrm{Ca}$ acts by strengthening cell walls (Larson et al., 1983). In cherries, repeated $\mathrm{Ca}$ sprays combined with GA applications were most effective, but protection was still incomplete. Calcium also has been sprayed on tomatoes with varying success (Dickinson and McCollum, 1964; Gill and Nandpuri, 1970; Igbokwe et al., 1987). Given the episodic nature of cracking in general, and the difficulty of getting compounds through the fruit cuticle, it is not surprising that success has been variable. Calcium applied to the fruit surface, for example, may penetrate only when moisture on the fruit surface is drawn into the fruit by nighttime contraction. Calcium sprayed on the foliage of tomatoes can damage the foliage (Dickinson and McCollum, 1964). Antitranspirants and osmotica also were sprayed on cherries to reduce cracking, but these attempts were largely unsuccessful (Flore, 1984).

Where should future research on tomato fruit cracking be concentrated3 Hypotheses proposed in this article that have not been tested directly include:

1) In summer-rain areas, maintaining a high soil-moisture level will reduce cracking. In other production situations, maintaining low soil moisture will be most effective.

2) Spraying tomatoes with GA compounds will reduce cracking because skin elasticity is increased.

3) When a sudden increase in soil moisture occurs, as in processing tomatoes at the end of the season, mechanical root pruning before the an ticipated rains will reduce cracking.

4) Development of the abscission zone in the tomato pedicel has a role in increasing the susceptibility of the fruit to cracking by progressively restricting water movement out of the fruit.

5) Forcing $\mathrm{Ca}$ into the fruit while still attached to the plant will increase the strength of the interlocular areas 
and reduce radial cracking.

6) The ratio of leaf area to fruit weight will affect cracking. In some cases, cracking could be increased and in others reduced. For example, a high ratio of leaf area : fruit might increase cracking because soluble solids increase. On the other hand, ample leaf area might reduce cracking because it provides greater shading and cooling of the fruit and greater loss of water through transpiration.

7) For a given cultivar, modeling of the water relations of the fruit will allow prediction of cracking based on ripeness, root pressure, temperature, humidity, and possibly availability of assimilates.

\section{Literature Cited}

Abbott, J.D., M.M. Peet, D.H. Willits, D.C. Sanders, and R.E. Gough. 1986. Effects of irrigation frequency and scheduling on fruit production and radial fruit cracking in greenhouse tomatoes in soil beds and in a soil-less medium in bags. Scientia Hort. 28:209-219.

Ackley, W.B. and W.H. Krueger. 1980. Overhead irrigation water quality and the cracking of sweet cherries. HortScience 15:289-290.

Andersen, P.C. and D.G. Richardson. 1982. A rapid method to estimate fruit water status with special reference to rain cracking of sweet cherries. J. Amer. Soc. Hort. Sci. 107:441-444.

Bakker, J.C. and J. Janse. 1988. Lage etmaaltemperatuur geeft meer kans op zwelscheuren bij tomaat. Weekblad Groenten en Fruit. 26 Feb. 1988. p. 30-31.

Brown, H.D. and C.V. Price. 1934. Effect ofirrigation, degree ofmaturity, and shading upon the yield and degree of cracking of tomatoes. Proc. Amer. Soc. Hort. Sci. 32:524-528.

Brown, K. and J. Considine. 1982. Physical aspects of fruit growth. Stress distribution around lenticels. Plant Physiol. 69:585590.

Byari, S.H. 1984. Physiological, genetic and breeding studies of tolerance to high temperature and high relative humidity in tomatoes (Lycopersicon esculentum Mill.). $\mathrm{PhD}$ Thesis, Univ. of Nebraska, Lincoln.

Byers, R.E., D.H. Carbaugh and C.N. Presley. 1990. 'Stayman' fruit cracking as affected by surfactants, plant growth regulators, and other chemicals. J. Amer. Soc. Hort. Sci. 115:405-411.

Calbo, A.G. 1990. Physiology of vacuum induced tomato fruit cracking. Revista Brasileira de fisiologia vegetal. 2:55-61.

Considine, J. and K. Brown. 1981. Physical aspects of fruit growth. Theoretical analysis of distribution of surface growth forces in fruit in relation to cracking and splitting. Plant Physiol. 68:371-376.

Considine, J.A. and P.E. Kriedemann. 1972. Fruit splitting in grapes: Determination of the critical turgor pressure. Aust. J. Agr. Sci. 23:17-24.

Corey, K.A. and Z- $\Upsilon$ Tan. 1990. Induction of changes in internal gas pressure of bulky plant organs by temperature gradients. J. Amer. Soc. Hort. Sci. 115:308-312.

Cortes, C., M.C. Ayuso, G. Palomares, J. Cuartero, and F. Nuez. 1983. Relationship between radial and concentric cracking of tomato fruit. Scientia Hort. 21:323-328.

Cotner, S.D., E.E. Burns, and P.W. Leeper. 1969. Pericarp anatomy of crack-resistant and susceptible tomato fruits. J. Amer. Soc. Hort. Sci. 94:136-137.

Cuartero, J., G. Palomares, S. Balasch, and F. Nuez. 1981. Tomato fruit cracking under plastic-house and in the open air. II. General and specific combining abilities. Genetics and Breeding of Tomato. Avignon, France, May 1981. (Proc. Meeting Eucarpia Tomato Working Group. p. 91-98.)

Dickinson, D.B. and J.P. McCollum. 1964. The effect of calcium on cracking in tomato fruits. Proc. Amer. Soc. Hort. Sci. 84:485-490.

Flore, J. 1984. The influence of irrigation on cracking of sweet cherries. 114th Annu. Rpt. of the Secretary of the State Hort. Soc. of Michigan. p. 208-212.

Fogle, H.W. and M. Faust. 1976. Fruit growth and cracking in nectarines. J. Amer. Soc. Hort. Sci. 101:434-439.

Frazier, W.A. 1934. A final study of some factors associated with the occurrence of cracks in the tomato fruit. Proc. Amer. Soc. Hort. Sci. 32:519-523.

Frazier, W.A. 1935. Further studies on the occurrence of cracks in tomato fruits. Proc. Amer. Soc. Hort. Sci. 33:536-541.

Frazier, W.A. 1952. Cracking resistance in puck progeny. Tomato Genet. Coop. Rpt. 2, p. 3.

Frazier, W.A. and J.L. Bowers. 1947. A report on studies of tomato fruit cracking in Maryland. Proc. Soc. Hort. Sci. 49:241-255.

Gill, P.S. and K.S. Nandpuri. 1970. Comparative resistance to fruit cracking in tomato (Lycopersicon esculentum Mill.). Indian J. Agr. Sci. 40:89-98.
Hankinson, B. 1979. Histological and physical behavior of tomato skins susceptible to cracking. J. Amer. Soc. Hort. Sci. 104:577-581.

Hepler, R.W. 1961. The measurement and inheritance ofresistance to fruit cracking in the tomato. PhD Thesis, Univ. of Illinois, Urbana.

Igbokwe, P.E., S.C. Tiwari, J.B. Collins, and L.C. Russell. 1987. Tomato cultivar response to foliar calcium and magnesium applications. J. Miss. Acad. Sci. 32:123131.

Kamimura, S. 1977. A method of testing crack resistance in tomatoes. Japan Agr. Res. Quarterly 11:111-114.

Kamimura, S. Yoshikawa, H. Ito, and K. Ito. 1972. Studies on fruit cracking in tomatoes. Bul. Hort. Res. Stat. Ministry Agr. For. Ser. C (Morioka) no. 7.

Lang, A. and H. During. 1990. Grape berry splitting and some mechanical properties of the skin. Vitis 29:61-70.

Lang, A. and M.R. Thorpe. 1989. Xylem, phloem and translocation flows in grape: Application of a technique for measuring the volume of attached fruits to high resolution using Archimedes principle. J. Expt. Bot. 40:1069-78.

Larson, F.E., R. Fritts, Jr., K. Patten, and M.E. Patterson. 1983. Sequential sprays of gibberellic acid and calcium may reduce cherry cracking. Goodfruit Grower 34:2628.

McCollum, J.P. and J. Skok. 1960. Radiocarbon studies on the translocation of organic constituents into ripening tomato fruits. Proc. Amer. Soc. Hort. Sci. 75:611616.

Schilstra-vanVeelen, I.M. and J.C. Bakker. 1985. Cracking of tomato fruits. 1985 Annu. Rpt. Glasshouse Crops Res. Expt. Stnd. Naaldwijk, The Netherlands. p. 39.

Simon, E.W. 1978. The symptoms of calcium deficiency in plants. New Phytol. 80:1-15.

Verner, L. 1935. A physiological study of cracking in 'Stayman' Winesap apples. J. Agr. Res. 51:191-222.

Walter, J.C. 1967. Hereditary resistance to disease in tomato. Annu. Rev. Phytopathology 5:131-162.

Young H. W. 1958. Inheritance of fruit cracking. Tomato Genet. Coop. 8:38. 